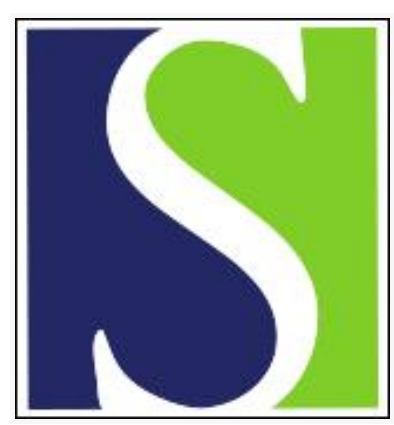

Scand J Work Environ Health 1999;25(5):442-449

https://doi.org/10.5271/sjweh.458

Issue date: Oct 1999

Reactions of healthy persons and persons suffering from allergic rhinitis when exposed to office dust

by Hauschildt P, Mølhave L, Kjærgaard SK,

The following articles refer to this text: 2003;29(6):411-430; SJWEH

Supplements 2008;(4):25-29

Key terms: epithelial cell defect; eye redness; human exposure; tear-film stability; threshold for eye irritation with carbon dioxide

This article in PubMed: www.ncbi.nlm.nih.gov/pubmed/10569465

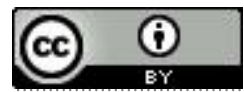




\title{
Reactions of healthy persons and persons suffering from allergic rhinitis when exposed to office dust ${ }^{1}$
}

\author{
by Pernille Hauschildt, MD, ${ }^{2}$ Lars Mølhave, PhD, ${ }^{2}$ SK Kjærgaard, PhD'
}

\begin{abstract}
Hauschildt P, Mølhave L, Kjærgaard SK. Reactions of healthy persons and persons suffering from allergic rhinitis when exposed to office dust. Scand J Work Environ Health 1999;25(5):442-449.

Objectives Reactions to airborne office dust among healthy subjects and subjects suffering from allergic rhinitis were investigated.

Methods Twelve healthy and 11 subjects suffering from allergic rhinitis were exposed to clean air [17 (SD 2) $\mu \mathrm{g} /$ $\mathrm{m}^{3}$ ] and office dust [439 (SD 68) $\mu \mathrm{g} / \mathrm{m}^{3}$ ] for 245 minutes. The effect measurements included subjective sensations (questionnaire and potentiometer ratings), mood scale, peak flow, bronchial provocation with histamine using forced expiratory volume in 1 second as the effect measure, nasal mucosal swelling, tear film stability, epithelial damage, foam formation in the eye canthus, threshold for eye irritation with carbon dioxide, eye redness, cellular content of conjunctival fluid, and an addition test for distraction. As many investigations were made and as many statistical analyses (including subgroup analyses) were carried out, the risk of mass significance appeared. This problem was dealt with using the Bonferroni correction for multiple significance tests.

Results The mean ratings of the potentiometer were higher (the subjects showed more irritation) during the dust exposure. The objective investigations showed only indications of effects of dust exposure, and some of the indications were in biologically unexplainable directions. No difference in the reactions to dust was observed between the healthy subjects and the subjects suffering from allergic rhinitis.

Conclusions Dust does not seem to have objective or subjective effects on humans, as only indications of dust effects were found. Subjects suffering from allergic rhinitis do not appear to be a risk group in relation to dust exposure.
\end{abstract}

Key terms epithelial cell defects, eye redness, human exposures, tear film stability, threshold for eye irritation with carbon dioxide.

House dust is found in normal, nonindustrial buildings in concentrations ranging from $10 \mu \mathrm{g} / \mathrm{m}^{3}$ to, in extreme cases, $1000 \mu \mathrm{g} / \mathrm{m}^{3}$ (1). Airborne dust in office buildings has been associated with symptoms of irritation of the eyes, nose, and throat (2). An experiment in a climate chamber has shown that healthy persons react with both subjective and objective responses to normal concentrations of house dust (3). Besides being discomforting for healthy persons, airborne dust may threaten the health of persons suffering from allergy or other hyperreactivity. Persons suffering from an allergy have more sensitive mucous membranes and react to smaller concentrations of irritants than normal persons do. Therefore, indoor climate problems are especially pronounced among such sensitive persons (4). In the Danish Town Hall Study it was shown that persons with allergic rhinitis had more work-related symptoms than nonallergic persons (5).

1 This article is partly based on a paper presented at the 'Indoor Air ' 96 ' conference in Nagoya, Japan.

2 Department of Environmental and Occupational Medicine, University of Aarhus, Aarhus, Denmark.

Reprint requests to: Dr Lars Mølhave, Department of Environmental and Occupational Medicine, Vennelyst Boulevard 6, University of Aarhus, 8000 Århus C, Denmark. [E-mail: 1m@mil.aau.dk]
The hypotheses of the present study were that house dust exposure is a cause of symptoms related to the sick building syndrome (irritative symptoms from eyes, nose, throat, airways, and skin, and symptoms like headache, tiredness, nausea, dizziness, and mental fatigue) as defined by the World Health Organization (6); any effect of dust can be measured objectively; and subjects suffering from allergic rhinitis will react stronger, objectively as well as subjectively, than healthy subjects.

\section{Subjects and methods}

\section{Subjects}

The study was a controlled, double-blind, cross-over experiment. The subjects, aged $18-50$ years, were recruited from the local population (through advertise- 
ments in a local newspaper), students at the university, and finally participants from previous experiments (the last-mentioned persons had been recruited in a similar manner). All the subjects were examined prior to the exposure study to ensure that they were healthy, had no drug or alcohol addiction, and were not smokers. To be included in the study as a healthy subject, the person could not have a history of allergic rhinitis or asthma, nor could there be any reaction on a standard prick test including 11 common allergens. Subjects suffering from allergic rhinitis had a typical history of seasonal hay fever symptoms, and the prick test was positive for either birch, timothy or mugwort. Subjects with positive prick test reactions to house dust mites (Dermatophagoides pteronyssinus and Dermatophagoides farinae), cat, horse or dog dander, or molds (Alternaria alternata, Cladosporium herbarum, and Aspergillus fumigatus) were excluded. All the subjects gave their informed consent in accordance with the Helsinki declaration. Further inclusion criteria were nonsmoking, normal lung function according to the Danish Lung Association (7), and a less than $10 \%$ decrease in forced expiratory volume during the first second $\left(\mathrm{FEV}_{1.0}\right)$ after provocation with $1.63 \mathrm{mg}$ of histamine. The selection of the subjects is summarized in table 1 . Twelve healthy subjects and 11 subjects suffering from allergic rhinitis participated. The study was intended to include 12 subjects suffering from allergic rhinitis, but 1 was excluded because of an acute infectious illness. The 2 groups of subjects were matched with respect to gender.

\section{Exposure}

Exposure was performed in a $32-\mathrm{m}^{3}$ stainless steel chamber. The exposures were aimed at dust concentrations of 0 and $400 \mu \mathrm{g} / \mathrm{m}^{3}$ and lasted 245 minutes. The dust concentration was measured gravimetrically using portable pumps (Du Pont Constant Flow Sampler Model S2500) and teflon filters. During the exposure the concentration of dust in the chamber was monitored by a Climet CI251 particle counter that reported the concentration of particles (numbers $/ \mathrm{m}^{3}$ ). Each subject wore a portable pump, and an additional filter was placed above each of them. The actual measured concentrations are shown in table 2 . The average daily temperature was 23.1 (range $22.8-23.2)^{\circ} \mathrm{C}$ and the relative humidity was 44.8 (range $43.6-45.8) \%$. The ventilation rate was 10 air changes per hour and lighting was kept constant and within normal limits. All the subjects were equipped with standard clothing, including dust-free protective clothing $(0.75$ clo). The dust was collected in normal offices at the University of Aarhus. Approximately 5 kilograms of dust was collected 1 month prior to the exposures. After being separated in a food processor and sifted in a $2.5-\mathrm{mm}$ sieve, 3210 grams was left. The preparation of dust and the exposure took place as previously described (8).

\section{Methods}

The sequence of measurements is shown in figure 1 . Subjective perceptions were registered on 2 versions of a visual analogue rating scale (9). The first method was based on a questionnaire presented in a computerized version. The questionnaire contained 36 questions concerning odor intensity, perception of the indoor climate, irritation symptoms in the eyes, nose and throat, and neurological symptoms such as headache and difficulties to concentrate. The subjects had to evaluate the acceptability of any effect of the exposure with a yes or no answer. According to the second method, the subjects used a linear potentiometer to quantify the sensation of irritation to the mucous membranes of the eyes, nose, and throat. The subjects were told to change the setting of the potentiometer whenever they felt any change in irritation. Every 30 minutes they were reminded by an acoustic signal to check the setting. In addition, a computerized mood-scale test was performed $(3,10)$. It is a self-administered questionnaire from which 5 dimensions of the subjects's mood, namely, anger, tension, depression, tiredness and confusion, during the previous 7 days is calculated. Peak flow was measured using a calibrated peakflow meter (model AIRMED, Mini Wright Peak Flow Meter). In the assessment of increased reactivity of the airways, bronchial provocation with histamine aerosols was used. $\mathrm{FEV}_{1.0}$ was used as the effect measure (11). To describe changes in the nasal mucosa, acoustic rhinometry was carried out (12). Tear-film stability (break-up time) was measured in cobalt blue light using $10 \mu \mathrm{l}$ of $1 \%$ sodium-fluorescein as the vital stain, and the

Table 1. Selection of subjects.

\begin{tabular}{lcc}
\hline & $\begin{array}{c}\text { Subjects } \\
\text { suffering } \\
\text { from allergic } \\
\text { rhinitis }\end{array}$ & $\begin{array}{c}\text { Healthy } \\
\text { subjects }\end{array}$ \\
\cline { 2 - 3 } & 73 & 47 \\
Invited for preliminary investigations & 3 & 5 \\
Failure to appear & 70 & 42 \\
Attendance at the preliminary investigations & 45 & 19 \\
Excluded because of prick test, histamine & 25 & 23 \\
provocation, or other illnesses & 3 & 5 \\
Accepted & 22 & 18 \\
Was not able or did not want to & & \\
participate in the study & & \\
Potential participants & & \\
\hline
\end{tabular}

Table 2. Measured dust concentration. ( $\mathrm{SD}=$ standard deviation)

\begin{tabular}{lrrrrrrrr}
\hline Method & \multicolumn{3}{c}{ Clean air $\left(\mathrm{mg} / \mathrm{m}^{3}\right)$} & & \multicolumn{3}{c}{ Dust $\left(\mathrm{mg} / \mathrm{m}^{3}\right)$} \\
\cline { 2 - 3 } \cline { 7 - 9 } & Mean & SD & Range & & Mean & SD & Range \\
\hline Stationary samplers & 17 & 2 & $14-20$ & & 439 & 68 & $322-502$ \\
Personal samplers & 21 & 12 & $6-37$ & & 376 & 46 & $315-421$
\end{tabular}




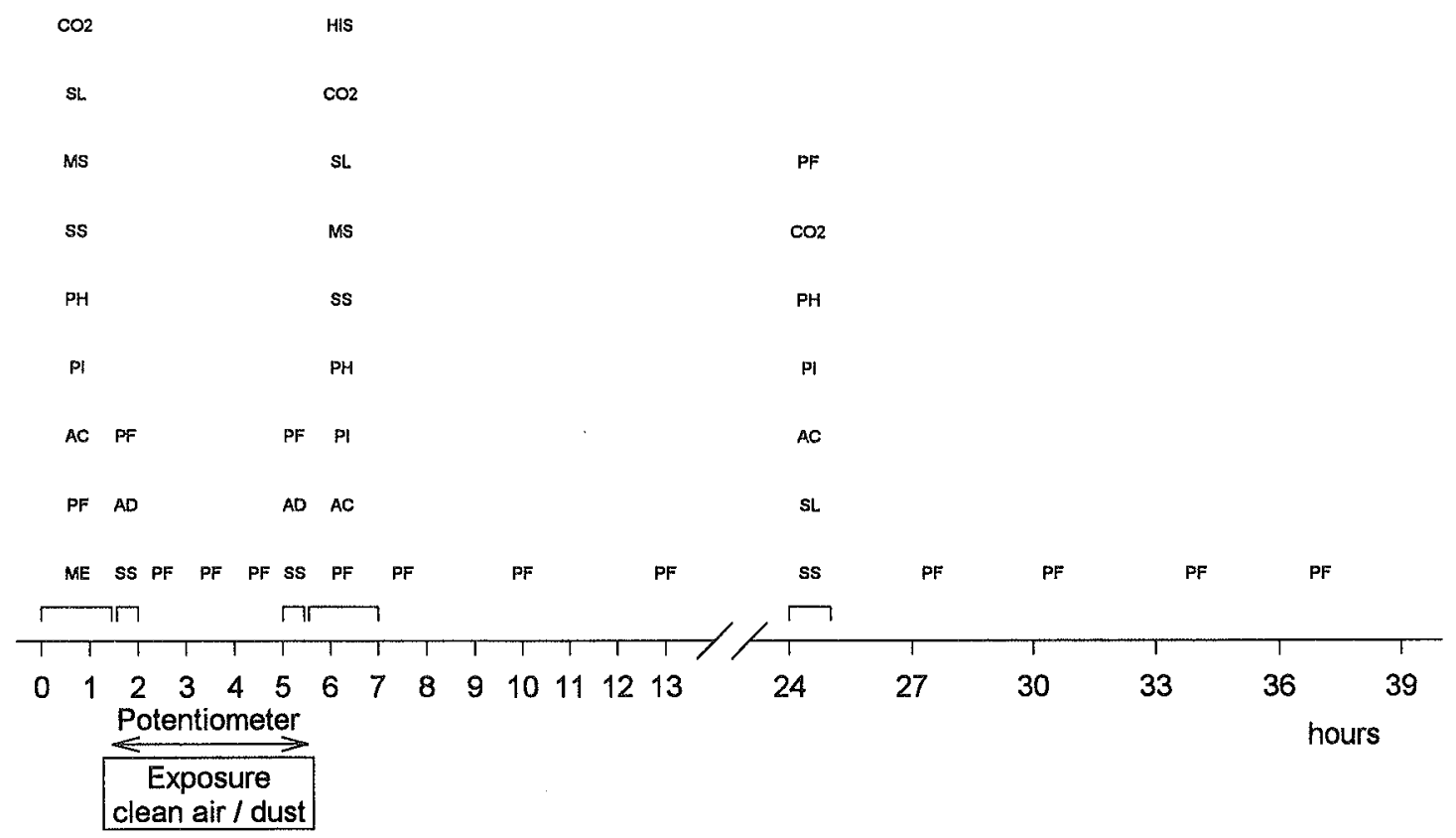

Figure 1. Time sequence of effect measurements. $\left(\mathrm{CO}_{2}=\right.$ carbon dioxide eye provocation test, $\mathrm{SL}=$ slit-lamp investigation, $\mathrm{MS}=$ mood scale, $\mathrm{PH}$ $=$ photograph of the eyes, $\mathrm{PI}=$ quantitative pipette method, $\mathrm{AR}=$ acoustic rhinometry, $\mathrm{PF}=$ peak flow, $\mathrm{ME}=$ medical examination, $\mathrm{AD}=$ addition test for distraction, $\mathrm{SS}=$ subjective sensations, HIS = histamine provocation)

mean of 3 consecutive measurements was calculated (13, 14). Epithelial damage was scored in 5 categories $(1=$ $0,2=1-10,3=10-504=50-100$, and $5=>100$ epithelial cell defects) in 4 different regions (medial, lateral, inferior and corneal) of the eye using $10 \mu \mathrm{l}$ of $1 \%$ lissamine green $(14,15)$. The mean of the number of epithelial cell defects in the 4 regions was used in the analysis. Foam in both the lateral and medial eye canthus was scored in 4 categories $(0=0,1=1-5,2=6-10$, and $3=>10$ foam bubbles) (14). The mean score was used in the analysis. The threshold for eye irritation with carbon dioxide was measured using eye goggles and exposing 1 of the eyes to increasing concentrations of carbon dioxide (ie, $0 \%, 4 \%, 8 \%, 16 \%$, and $32 \%$ ) (16). The bulbar medial conjunctiva of each subject was photographed for an assessment of eye redness. For evaluation, pairs of photographs, taken before, right after, or the day after, were randomized and compared by a panel of staff members (16). The cellular content of the conjunctival fluid was estimated by use of the quantitative pipette method $(14,17)$. Baseline samples and a sample after each exposure period were obtained from the lateral inferior fornix (under the lower eyelid). The material was washed out and fixed on a glass-slide using $10 \%$ formaldehyde and stained with May Grünwald Giemsa stain. The total numbers of polymorphonuclear leukocytes, lymphocytes, and squamous and cuboidal cells were counted by microscopy (400-1000 X). Furthermore, an addition test for distraction was carried out. It was used as a measure for difficulties in concentration (3). The total number of calculations and the reaction time were used as the effect parameters.

\section{Statistical methods}

A screening procedure was used to reduce the number of covariates. It had the following generic form: response $=X \cdot$ (covariates $)+$ error $(1)$. Here $X$ is a coefficient, describing the relation between the response and the variables. In the final analyses, a mixed model analysis was used. The level of confidence was $5 \%$. The standard statistical model can be written as follows: response = $X_{1} \cdot(\mathrm{AR})+X_{2} \cdot($ exposure $)+X_{3} \cdot(\mathrm{AR} \times$ exposure $)+$ $X_{4} \cdot$ (covariates $)+X_{5} \cdot($ covariates $\times$ exposure $)+X_{6} \cdot($ covariates $\times \mathrm{AR})+Z \cdot($ person $)+\operatorname{error}(2)$. The $X_{i}^{\prime}$ 's describe the relation between the response and the variables. They influence the average of the response. $Z$ influences the variance of the response. AR describes the presence or absence of allergic rhinitis. Not normally distributed data were logarithmicly transformed.

The 4 last replies of the questionnaire were analyzed together after the basis ratings had been subtracted. Therefore a new variable was introduced into the analysis, namely, a time factor which specified in which run the questionnaire was answered. This factor was analyzed in interaction with all the other effects. In the analysis of the acceptability questions (yes;no) log-linear analysisof-frequency tables were used. 
Whenever data were missing, numbers, which allowed sums of squares of deviations (SSD) in the model to be unchanged, replaced missing data. This procedure introduces the risk of bias into the analysis, but this bias is estimated to be too small to change the final conclusions of the experiment. In the analyses the Statistical Analysis System (SAS) and Statistica were used.

The significance level was adjusted according to the Bonferroni correction based on the number of tests done on a single data set leading to a significance level of 0.0001 (18). However, in the Results section, the effects with significances below 0.05 are mentioned.

\section{Results}

Only effects in relation to the sick-building syndrome in the questionnaire are described.

The visual analogue scale showed that throat irritation was higher during the clean-air exposure than during the dust exposure $(\mathrm{P}=0.01)$. Both healthy subjects and subjects with allergic rhinitis had less nose irritation when exposed to dust than when exposed to clean air $(P=0.01)$. Both groups had a greater well-being just after entry into the chamber during the dust exposure $(\mathrm{P}=0.03)$.

The healthy subjects accepted mucous membrane symptoms to a greater extent, for example, eyes watering, sand in eyes, throat irritation, mouth irritation, sensations of coughing or sneezing, and general mucous membrane irritation.

According to the potentiometer the intensity of the mucous membrane symptoms was higher when the subjects were exposed to dust (mean of all ratings) $(\mathrm{P}=0.0001)$. The women felt less irritation than the men ( $\mathrm{P}=0.03$ ) (figure 2). The women reported more irritation during dust exposure than during the clean-air exposure, while the men had slightly decreased irritation during the dust exposure. No significant effects of dust were seen in the ratings from the first or last 6 minutes of exposure.

Five different measurements of the subjects' mood and the integrated measure constituted the 6 responses on the mood scale. An increased rating of anger during the last week was seen on the mood scale after the dust exposure ( $\mathrm{P}=0.02)$. The subjects suffering from allergic rhinitis rated more anger than did the normal subjects $(\mathrm{P}=0.02)$.

No effects of dust were seen with respect to peak flow and acoustic rhinometry.

After the dust or clean-air exposure the $\mathrm{FEV}_{1.0}$ was measured before (baseline) and after provocation to 3 concentrations of histamine. The baseline $\mathrm{FEV}_{1}$ was lower after the exposure to clean air when compared with the exposure to dust $(\mathrm{P}=0.0005)$. The $\mathrm{FEV}_{1.0}$ decreased after histamine provocation, but the decrease was not affected by the dust exposure.

Immediately after the exposure the tear-film stability decreased $(\mathrm{P}=0.04)$. The decrease was largest after the clean-air exposure. The tear-film stability of the healthy persons decreased more than that of the allergic subjects $(\mathrm{P}=0.01)$.

Epithelial cell defects were decreased just after exposure when compared with the base-line measure $(\mathrm{P}=0.01)$. The decrease was largest after the clean-air exposure. The next day the epithelial cell defects were still reduced after the clean-air exposure, while they had increased among the subjects who had been exposed to dust (figure 3).

No effect of dust was seen on the number of foam bubbles in the eye canthus immediately after exposure. For the late value an interaction between exposure and corneal wounds was significant $(\mathrm{P}=0.01)$. The number of foam bubbles decreased after the clean-air exposure and increased after the dust exposure. The presence of corneal wounds meant a higher number of foam bubbles.

The eye irritation responses recorded at $8 \%, 16 \%$, and $32 \%$ concentrations of carbon dioxide were logarithmized and analyzed independently of each other. An exposure effect was observed for $32 \%$ carbon dioxide $(\mathrm{P}=0.0026)$. The effect was seen immediately after the exposure and in interaction with previous smoking status (ex-smoking yes;no). After the dust exposure the sensitivity to carbon

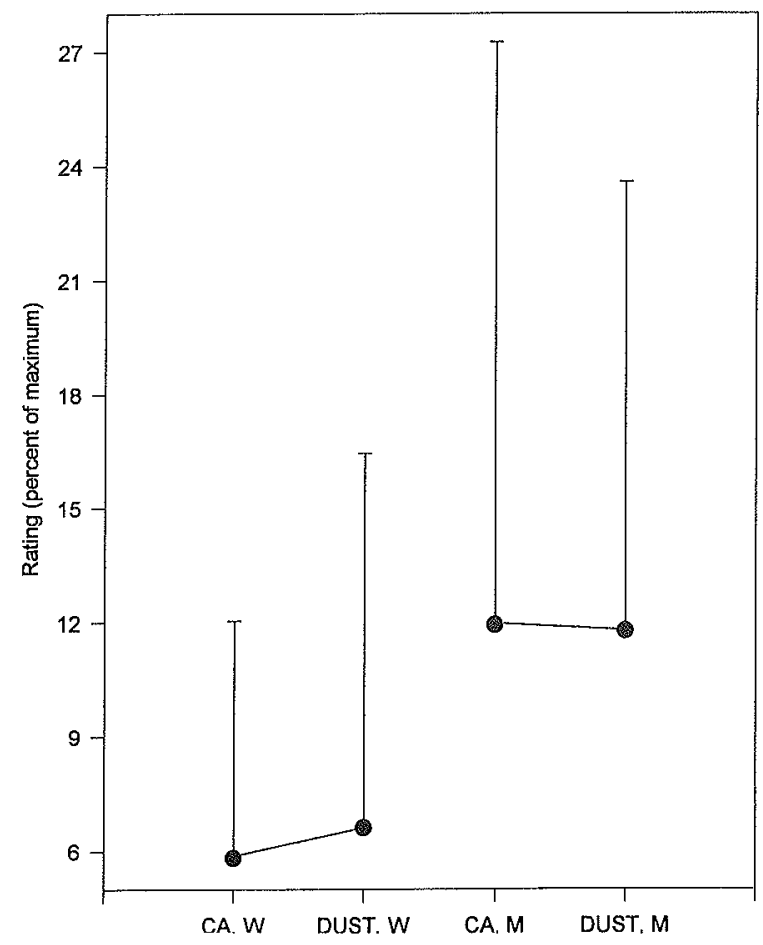

Figure 2. Average rating on the potentiometer (and standard deviations) according to exposure type (dust/clean air $=C A$ ) and gender $($ women $=\mathrm{w}$, men $=\mathrm{m})$. 


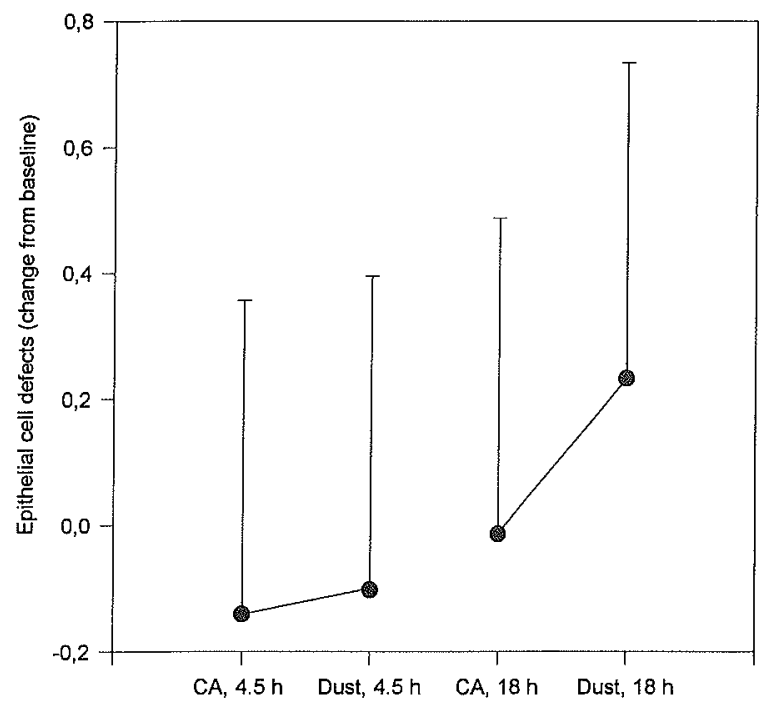

Figure 3. Average number of conjunctival epithelial cell defects (measured as lissamine-green-stained dots) according to exposure type (CA = clean air) and time of measurement (standard deviations included).

Table 3. Observed mean difference (corrected for base-line values) and calculated minimum detectable difference. (acute = measurement immediately after entry to the chamber, subacute $=$ measurement at the end of exposure, FEV $V_{t .0}=$ forced expiratory volume in 1 second )

\begin{tabular}{lcc}
\hline Parameter measured & $\begin{array}{c}\text { Observed } \\
\text { mean } \\
\text { difference } \\
\left(\Delta_{\text {dust }}-\Delta_{\mathrm{CA}}\right)\end{array}$ & $\begin{array}{c}\text { Minimum } \\
\text { detectable } \\
\text { difference }\end{array}$ \\
\hline Tear-film stability, subacute (s) & 0.4 & 37 \\
FEV $_{1.0}()^{\text {a }}$ & 0.06 & 0.38 \\
Peak flow, acute (l/min) & 1 & 52 \\
Acoustic rhinometry (minimum & 0.02 & 0.33 \\
cross-sectional area), subacute $\left(\mathrm{cm}^{2}\right)$ & 0.53 & 5.2 \\
Acoustic rhinometry (volume), subacute $(\mathrm{ml})$ & -1 & 8 \\
Potentiometer, first 3 ratings (\%) & -0.3 & 4.1 \\
16\% carbon dioxide, subacute (\%) & -1 & 3 \\
Addition test, errors, subacute (\%) & 148 \\
Addition test, total number of calculations, subacute-18 & 18 \\
Eye redness, subacute & -0.25 & 4.1 \\
\hline
\end{tabular}

a No base-line correction.

dioxide at $32 \%$ increased for all the subjects. An increase in the sensitivity to carbon dioxide was also seen after the clean-air exposure for "never smokers", while exsmokers experienced a decreased sensitivity to carbon dioxide after the clean-air exposure in comparison with the base-line level.

The results for eye redness were transformed according to the equation $\log \left(x+10^{4}\right)$. There were no effects immediately after the exposure. Both former and never smokers had increased eye redness after the dust exposure ( $\mathrm{P}=0.01)$, but the effect of dust was the most pronounced among the former smokers.
The results of the quantitative method were logarithmized before the analysis. For polymorphonuclear leukocytes an effect of dust in interaction with the allergic rhinitis status was seen $(\mathrm{P}=0.008)$ right after the exposure. The number of polymorphonuclear leukocytes increased among the healthy subjects after the dust exposure when compared with the number occurring after the clean-air exposure, while the opposite was true for allergic subjects. The same pattern was seen for the number of squamous epithelial cells $(\mathrm{P}=0.003)$. The number of cuboidal cells was not affected by the dust exposure. None of the cell types were affected the day after exposure.

There was no effect of dust on the total number of calculations performed in the addition test or on the average reaction time. The effect of dust on the number of errors, right after the start of the exposure, appeared to interact with the amount of coffee or tea consumption $(\mathrm{P}=0.003)$. At the end of the exposure, dust exposure resulted in a lower number of mistakes than did the cleanair exposure $(\mathrm{P}=0.04)$.

\section{Discussion}

Only a few effects of dust were found, many of which were in interaction with covariates. Furthermore, several were unexplainable because of being in directions that were the opposite of what was expected. The minimum detectable difference, expressing the test power of the study indirectly, was calculated using a paired sample ttest for differences between dust and clean-air exposure (19). The values for $\alpha$ and $\beta$ were 0.05 and 0.2 , respectively, test power $=1-\beta=0.8$. The results can be seen in table 3 . The calculated minimum detectable difference was larger for all the measurements than the actually observed difference; this finding indicates that either the number of subjects was too small or the observed variance was too large. A way to strengthen the study could be to increase the number of subjects. Furthermore, the variance could be reduced by selecting subjects from a more homogeneous population (eg, same age or gender), conducting investigations by the same investigators, using the same equipment for the same investigations, and doing the same investigations at the same time of the day. However, almost all the investigations were carried out by the same investigators, using the same equipment, doing the investigations at the same time of day. As so, it would not be easy to reduce the variance, and the best solution would be to make a larger study using more subjects.

Whenever a large number of statistical analyses are done on the same data set, the risk of mass significance appears, and, therefore, when a confidence level of 0.05 
is used, 1 out of 20 analyses will appear as "significant". The Bonferroni method of correcting for this situation depends on calculations of a new significance level based on the accepted $\mathrm{P}=0.05$ divided by the number of analyses carried out. The battery of tests led to 110 variables to be tested statistically. Including covariates in the analyses led to a total number of analyses of 406 . Correction gives a P-value significance of 0.0001 . However, the Bonferroni method is conservative and introduces the risk of overlooking true effects (18). Supposing dust exposure had an effect on the eyes, and nowhere else, the significance level of the eyes would be lowered due to searching for an effect on other organs. This situation demands a pronounced effect of dust on the eyes to be revealed. It seems fairer that the division of subjects into different groups requires a lower level of significance. Anyway, in consideration of the nature of the results, the discussion focuses on results with a significance level of 0.0001 . Results with levels of significance between 0.0001 and 0.05 are referred to as tendencies.

\section{The first hypothesis (house dust is causative agent for symptoms related to sick-building syndrome)}

The WHO definition for the sick-building syndrome includes only symptoms and no objective criteria (6). Therefore only the questionnaire and the potentiometer ratings can, in this study, confirm or disprove whether dust exposure leads to symptoms of this syndrome. The results from the questionnaire point towards no effect of dust or even a slight tendency towards the subjects having fewer symptoms during dust exposure than during clean-air exposure. In the potentiometer ratings the intensity of the mucous membrane symptoms was higher when the subjects were exposed to dust. A tendency towards a difference between the ratings among the men and women was seen. The potentiometer supported the possibility that dust can lead to symptoms of the sickbuilding syndrome, but it was not confirmed by the questionnaire, and the results must therefore be interpreted with caution.

\section{Second hypothesis (effect of dust can be measured objectively)}

No objective investigations were significant according to the Bonferroni-corrected $\mathrm{P}$-value. Tendencies were found, however. For most of the investigations they were the opposite of known or expected effects, and therefore they need confirmation.

It is possible that dust exposure only affects a subgroup of people, as discussed by Mølhave et al (3). If true, it could explain some of the missing direct dust effects and form the basis for an alternative hypothesis concerning sensibility to dust exposure. The only group which showed a tendency towards a difference between clean-air and dust exposure was former smokers, and this group consisted of only 6 persons. Dust exposure was expected to result in increased eye redness, whereas clean-air exposure was expected to have no effect on eye redness. Both never smokers and ex-smokers showed a tendency towards redder eyes after exposure to dust than to clean air. The effect was not seen on the day of exposure, but, as the mechanisms resulting in red eyes are complicated and not known in detail, a delayed effect may occur. In general, inflammatory responses are known to be delayed $(20,21)$. Increased eye redness has also been found after exposure to tobacco dust (22), n-butanol (990 ppm) (23), and 1-octene (3922 ppm) (23), while other studies involving exposure to n-decane (13) or office dust (3) showed no effect on eye redness. These results suggest that exposure has to be pronounced to reveal any effect or that the mechanisms producing red eyes are not simple. In a study of pollen exposure, a biphasic effect was found on eye redness with initially decreased redness after provocation with half of the provoking dose, and also increased eye redness after the full dose (16). The decreased redness was suggested to be caused by a trigeminal-reflex-mediated response, systemic release of vasoconstrictors in the blood, or some unknown, locally released substance. The present dust-exposure study did not include smokers; therefore any effect of smoking status is an effect of whether the subject had previously been smoking regularly or not. As the results are somewhat contradictory in relation to which subgroup is the most sensitive and as the found effects are only tendencies, the conclusion is that no special sensitivity was found in any subgroup.

\section{Third hypothesis (subjects suffering from allergic rhinitis will react stronger than healthy subjects)}

The subjects suffering from allergic rhinitis showed a tendency towards a less acceptability of symptoms of exposure. But they evaluated the symptoms of the exposure as equal to or less than those of the healthy subjects. Only healthy subjects showed a tendency towards increases in the number of polymorphonuclear leukocytes and squamous epithelial cells as expected. However, the preexposure level of cells was higher among the allergic subjects (preexposure average number of polymorphonuclear leukocytes among the subjects suffering from allergic rhinitis $=23$ against the preexposure average number of polymorphonuclear leukocytes among the healthy subjects $=1$ ), and, therefore, the most probable effect of any exposure had to be a decrease of cells as regression towards the mean. The expected effect was only seen for half of the subjects and was not significant due to the Bonferroni-corrected significance level and therefore needs confirmation. Effects on polymorphonuclear leukocytes are thought to be signs of subclinical chemical conjunctivitis due to migration of the polymorphonuclear leukocytes from the vessels, whereas epithelial cells have 
been shown to be able to be destroyed by mechanical actions from, for example, man-made mineral fibers (24). In conclusion, it was not shown that subjects with allergic rhinitis are more sensitive to dust exposure, neither was it found that they reacted objectively stronger.

Another reason for not finding effects of dust exposure could be that dust in the concentrations used in this study is of no significance to the perception of air quality, or the concentration was too small to cause changes in objective measures. Several studies, epidemiologic as well as experimental $(2,3,22,25)$, point, however, in the direction of an effect of exposure to dust or at least exposure to different components of dust $(26,27)$. The composition of the dust in this study was, because of economic reasons, not examined with respect to these details. The size of the dust particles used for exposure is probably of importance with respect to reactions among subjects exposed to the particles. In our study the size of the particles was not measured but was expected to be of the same size as in another dust exposure study (unpublished observations), in which the same procedures were used when preparing and exposing the dust. Eighty percent of the particles in that study had a diameter of less than $10 \mu \mathrm{m}$. Particles between 1 and $10 \mu \mathrm{m}$ are expected to be deposited in both the upper and lower airways (28, 29 ) and should be able to exert an effect where deposited.

In conclusion, indications of dust effects were found, but the study does not support the possibility that dust, in this concentration and quality, has objective or subjective effects on humans. No difference in the reactions to dust was observed between healthy persons and persons suffering from allergic rhinitis. The reason for missing dust effects could be that dust in the concentrations used for exposure has no effect on humans or the study included too small a number of subjects to detect dust effects.

\section{Acknowledgments}

The study was supported by a grant from the Danish Medical Research Council (J nr 12-14931).

\section{References}

1. Wallace L. Indoor particles: a review. J Air Waste Manage Assoc 1996;46:98-126.

2. Armstrong $\mathrm{CW}$, Sheretz PC, Llewellyn GC. Sick building syndrome traced to excessive total suspended particulates (TSP). In: Proceedings of the ASHRAE/SOEH Conference, IAQ 89 1989:3-7.

3. Mølhave L, Kjargaard SK, Attermann J, Pedersen OF. Hus- støv og indeklima. ̊̊rhus (Denmark): Aarhus Universitets Trykkeri, 1995: 1-238.

4. Weeke B. Medicinsk-allergiske sygdomme. In: Thaysen JH, Lorenzen I, Christensen LK, editors. Medicinsk Kompendium. 13th ed. Copenhagen: Nyt Nordisk Forlag Arnold Busch, 1986:68-91.

5. Skov $P$, Valbjøm $O$. The "sick" building syndrome in the office environment: the Danish town hall study. Environ Int 1987; 13:339—49.

6. Work Health Organization (WHO). Indoor air pollutants: exposure and health effects. Copenhagen: WHO, 1982.

7. The Danish Association for Lung Medicine. Reference values for lung function among Danish men and women. Copenhagen: The Danish Association for Lung Medicine, 1986:117.

8. Mølhave L, Strien Rv. Støveksponeringer i klimakammer. Århus (Denmark): Aarhus Universitets Trykkeri, 1991:168.

9. Mølhave L, Bach B, Pedersen OF. Human reactions to low concentrations of volatile organic compounds. Environ Int 1986; 12:167-75.

10. Kjærgaard SK, Rasmussen TR, Mølhave L, Pedersen OF. Luftforurening og allergi. Et særligt behov for beskyttelse? Århus: Aarhus Universitets Trykkeri;1995;1-61.

11. Yan K, Salome C, Woolkock AJ. Rapid method for measurement of bronchial responsiveness. Thorax 1983;38:760-5.

12. Hilberg O, Jackson AC, Swift DL, Pedersen OF. Acoustic rhinometry: evaluation of nasal cavity geometry by acoustic reflection. J Appl Physiol 1989;66:295-303.

13. Kjærgaard SK, Mølhave L, Pedersen OF. Human reactions to indoor air pollutants: n-decane. Environ Int 1989;15:47382.

14. Norn MS. The external eye: methods of examination. 2 nd ed. Copenhagen: Scriptor Publisher, 1983:1-212.

15. Kjærgaard SK. Assessment methods and causes of eye irritation in humans in indoor environment. In: Knöppel $\mathrm{H}$, Wolkoff P, editors. Chemical, microbiological, health and comfort aspects of indoor air quality — state of the art in SBS. Brussels, Luxembourg: Kluwer Academic Publishers 1992:115-27.

16. Kjærgaard SK, Pedersen OF, Taudorf E, Mølhave L. Assessment of changes in eye redness by a photographic method and the relation to sensory eye irritation. Occup Environ Health 1990;62:133-7.

17. Kjærgaard SK, Pedersen OF. Dust exposure, eye redness, eye cytology and mucous membrane irritation in a tobacco industry. Int Arch Occup Environ Health 1989;61:519-25.

18. Bland M. An introduction to medical statistics. 2nd ed. New York (NY): Oxford Medical Publications, 1996.

19. Zar JH. Biostatistical analysis. 3rd ed. Upper Saddle River (NJ): Prentice Hall, 1996.

20. Koren HS, Devlin RB. Human upper respiratory tract responses to inhaled pollutants with emphasis on nasal lavage. Ann NY Acad Sci 1992;641:215-24.

21. Koren HS, Graham DE, Devlin RB. Exposure of humans to a volatile organic mixture, III: inflammatory response. Arch Environ Health 1992;47:39-44.

22. Kjærgaard SK, Pedersen OF, Frydenberg M. Respiratory disease and lung fuction in a tobacco industry. Arch Environ Health 1989;44:164-70.

23. Hempel-Jørgensen A, Kjærgaard SK, Mølhave L. Cytological changes and conjunctival hyperemia in relation to sensory eye irritation. Int Arch Occup Environ Health 1998;71(4):22535. 
24. Stokholm J, Norn M, Schneider T. Ophthamologic effects of man-made mineral fibers. Scand J Work Environ Health 1982;8:185-90.

25. Skov P, Valbjørn O, Pedersen BV, The Danish Indoor Climate Study Group. Influence of personal characteristics, jobrelated factors and psychosocial factors on the sick building syndrome. Scand J Work Environ Health 1989;15:286-95.

26. Teeuw KB, Vandenbroucke Grauls CM, Verhoef J. Airborne gram-negative bacteria and endotoxin in sick building syndrome: a study in Dutch governmental office buildings. Arch
Intern Med 1994;154:2339_ 45.

27. Raw GJ, Roys MS, Whitehead C. Sick building syndrome: cleanliness is next to healthiness. Indoor Air 1993;3:237-45.

28. Owen MK, Ensor DS. Airborne particle sizes and sources found in indoor air. Atmos Environ 1992;26A:2149—62.

29. Autrup H, Bonde JP, Rasmussen K, Sigsgaard T. Miljø- og arbejdsmedicin. 1st ed. Århus (Denmark): FADL's forlag, 1998.

Received for publication: 29 July 1998 